\title{
Four
}

\section{MOORE'S METAETHICS: THE SCIENCE OF GOOD}

The direct object of Ethics is knowledge and not practice.... It is with reasons that we are chiefly concerned in any scientific Ethics. ${ }^{1} \mathrm{G}$. E. Moore

Those who have labored at the task of collecting and classifying value theories have ordered them in admittedly arbitrary ways or, at least, in no systematic fashion. ${ }^{2}$ In their collection of Readings in Ethical Theory, Wilfrid Sellars and John Hospers, after an introductory essay by Bertrand Russell on "The Elements of Ethics," and G. E. Moore's "Utilitarianism" as "a sample ethical theory,"” turn to Moore's naturalistic fallacy. ${ }^{4}$ They then proceed through "the development of ethical intuition," the "naturalistic rejoinder," the "emotive theory," "the psychology of conduct and the concept of obligation," "moral freedom, guilt, and responsibility," to "the problem of justification." Sellars and Hospers are aware of the haphazard nature not only of their classification as a whole, but also of that of assigning certain essays to one rather than to another section. Thomas Hill arranges the subject "in terms of...the meanings of the moral predicates" in the following six sections:

Skeptical theories, according to which ethical predicates have no intelligible meaning at all but are merely emotive expressions;

Approbative theories, in which these predicates are partly intellectual and partly emotional approvals and disapprovals;

Process theories, in which moral concepts refer to the furthering of some observable dynamic process which, being always incomplete, forbids fixed moral definition;

Psychological Value theories, in which good refers to psychological states of desire, interest, or feeling, while right refers to their promotion;

Metaphysical theories, in which moral concepts refer to relations to such ultimate being as cannot be empirically apprehended;

Intuitive theories, in which one or more moral predicates are unique and, though applicable to specific kinds of experience, not reducible to them. ${ }^{5}$

Hill ends his classification where Sellars and Hospers begin theirs, with Moore and the intuitionist.

Moore's theory has a distinguished place both in Sellars and Hospers as a point of departure and in Hill as a point of arrival-but for different reasons, which may be called chronological and logical, respectively. Sellars and Hospers 
begin with Moore simply because he started the present phase of ethical debate, and it was their aim "to provide a balanced and first-hand account of the theoretical controversies that have developed in ethics since the publication in 1903 of Moore's Principia Ethica."' Hill regards Moore's theory as more systematic than the other theories in two respects, (1) its coherent interpretation of moral experience and (2) its coherent interpretation of interpretations of that experience.

This formulation makes evident what a language of value ought to be and why the classifications of value theories so far have not been systematic. If the ideal language of value ought to surpass other languages of value in its power not only of interpreting moral experience but also its power of interpreting interpretations of such experience, it must be the ethical theory that is on the highest level of discourse. Moore called a language the subject matter of which is a moral experience an "Ethics." A language whose subject matter is an ethics is a "meta-ethics" and one whose subject matter is a meta-ethics a "meta-metaethics." The language of value must at least be a meta-meta-ethics.

This fact-or rather "ought"-makes clear why classifications of ethical theories thus far have not arrived at a systematic order. A meta-meta-ethics, as any "meta-meta," must be more formal than either an ethics or a meta-ethics. The only arrangement that could arrive at a systematization of ethical theories would be a formal arrangement, that is, one that arranges these theories not according to their content but according to their form. Both Sellars and Hospers, and Hill arrange these theories according to content and not form. This is important not only for understanding the connections between these theories, but also for understanding these theories themselves. The material viewpoint is apt to misunderstand the particular significance of a value theory. Hill, although he does recognize and describe the superiority of Moore's theory and the corresponding inferiority of the other theories, misunderstands the reason for the superiority of Moore's theory and the inferiority of the other theories: the formal nature of Moore's theory. It is on a higher level of discourse than the other five theories; it deals not with things that are good but with the predicate "good." It is metaethics rather than ethics. Recall that for Brand Blanshard the higher abstraction of Moore's theory is its failure rather than its merit.

Thus, already from the outset, Moore's theory is superior to interpretations of moral experience on the level of ethics. It is not, however, a meta-meta-ethics. This it would be if it were able completely, coherently, and consistently to analyze in its own terms not only all the other value languages, but also the value experience itself. In that case it would be the system of value which the ideal value language ought to be. It would be on the third, not the second, level of value analysis. Whereas the third level is autonomous and creative of value language-in analyzing other value languages in its own terms and according to its own systematic - the second level is general enough to analyze first-level descriptions of value experience but not coherent and consistent enough to systematize them. Moore's value theory is general enough to analyze empirical 
value languages, but not systematic enough to order them autonomously. Moore was well aware of this. He wrote Principia Ethica not as the future systematic science of ethics but as the prolegomena to such a science: "I have endeavored to write 'Prolegomena to any future Ethics that can possibly pretend to be scientific."' He opened up Ethics; he did not give it systematic closure. All he wanted to do was to keep Ethics open to investigation and not to preclude its study through initial definition of its fundamental term. ${ }^{8}$ His theory was a promise and a pointer-a meta-ethics pointing toward a meta-meta-ethics. Ludwig Wittgenstein said, "What Moore primarily did, as a philosopher, was to "destroy premature solutions' of philosophical problems." If Hill's opinion about the promise of Moore's theory is correct, ${ }^{10}$ then Moore achieved what he set out to do.

Actually, he achieved much more than either he or any of his interpreters supposed. He laid the foundations of a science of Good.

\section{Moore's Axiomatic of the Science of Ethics}

Moore's doctrine of the undefinability of good has occasionally been misunderstood as meaning that good is indefinable because it is not clear, that it could not be clear because it is not accessible to rational understanding. Even Moore himself (in his debate with Charles L. Stevenson) ${ }^{11}$ for a very short moment in his life ${ }^{12}$ doubted that it was and faltered in his intuition of the self-evident clarity of this notion. Compare his doubt about his theory that good is an object like number with Gottlob Frege's doubt about his theory that numbers are objects. ${ }^{13}$ With this one exception, he steadfastly kept to the conviction expressed in Principia Ethica that the notion of good is so simple as to be incapable of proof, so transparently clear as to be in no need of proof, so self-evident as to be understood as soon as it is mentioned (at least to non-philosophers ${ }^{14}$ ), so unique as to belong to nothing but Ethics, and so fundamental as to serve as basis for a systematic science.

Anyone familiar with the concept of a systematic science, on reading Moore's account, ought immediately to conclude that his notion of good had all the characteristics of an axiom, and that all that is needed to bring about the systematic science of Ethics would be to articulate this notion so as to form this axiom and to deduce the science from it. But nobody, so far, including Moore, has seriously entertained this idea, and no one has drawn its consequences. Yet, and this is the burden of this chapter, Moore developed his original notion of good as if it were the concept of an axiom; and he actually gave a formula that could constitute the axiom of a future science of Ethics.

Although Principia Ethica arose from the study of Immanuel Kant's Ethics, Moore's model of a science is not Kant's moral science, but Sir Isaac Newton's natural science. In writing "Prolegomena to any future Ethics that can possibly pretend to be scientific," Moore paraphrased Kant's foundation of pure, not of practical, Reason. The title of Principia Ethica follows Newton's title, Principia 
Mathematica. As Newton conceived of a systematic science of nature, so Moore, equally clearly but incomparably less distinctly, conceived of a systematic science of Ethics. As Newton laid the foundations of his science in Philosophiae Naturalis Principia Mathematica, so Moore wrote the "Prolegomena" to his in Principia Ethica, that is, Philosophiae Moralis Principia Ethica. He conceived of Ethics as the systematic frame of reference that orders moral phenomena as mathematics, according to Newton and Kant, orders natural phenomena. Good, says Moore, is the basic notion of the systematic science of Ethics. It belongs to the same class of objects as does number. ${ }^{15}$ Moore did not hold, as did Plato, Alfred North Whitehead, and others that goodness and number are one and the same, but only that they are of the same kind. Though he rarely bothers about the relation between number and goodness, ${ }^{16}$ as Plato and Whitehead did on principle, Moore certainly would agree that as Number is the basis of the system of Mathematics, so Goodness is the basis of the system of Ethics.

The structure of the science of Ethics is to parallel that of such "sciences as physics, chemistry, and physiology in their absolute distinction from those of which history and geography are instances." 17 "These latter are sciences which deal with unique, individual, absolutely particular fact," ${ }^{18}$ while "the subjects of the judgments of a scientific Ethics are not...'particular things'; but it includes all universal judgments which assert the relation of 'goodness' to any subject."19 The science of Ethics does not merely deal with good conduct, or with this or that which is good; it deals with goodness itself. "I am using [Ethics] to cover an enquiry for which, at all events, there is no other word: The general enquiry into what is good." ${ }^{20}$ This science should be applicable to anything called good, whether individual things or classes of things. In the first case, the ethical system must contain reasons and principles sufficient for deciding on the truth "of all the many million answers" given to the question "What is good?" when it is said: "This is good." But, strictly speaking, "this is not the sense in which a scientific Ethics asks the question," just as, strictly speaking, it is not the meaning of physics to ask what is the strength of this particular dam. Rather, scientific Ethics is concerned with the general question "What is good?" applied to classes of things, for example, whether the enjoyment of pleasure is good-just as physics is concerned in hydrodynamics with the general question of the forces of water against any kind of dam. The application of Ethics to such general questions is Casuistry. Ethics, thus, is the theoretical science, while Casuistry is the corresponding applied science. Both alike deal with what is general, in the sense in which physics and chemistry deal with what is general.

Besides the application of Ethics to individual and general value situations, there is Ethics itself, based on a third meaning of the question "What is a good?" in the sense of "not what thing or things are good, but how 'good' is to be defined." 21 This question is different in kind from the first two. In the answers to the first two, "good" is the predicate, whereas in the answer to the third "good" is no predicate, but either the subject, if the answer is "Good is...," or 
the definiendum of a definition. The science that deals with this third question, therefore, is different in kind from Casuistry. It is Ethics proper. How "good" is to be defined "is an inquiry which belongs only to Ethics, not to Casuistry." Casuistry is the goal of ethical investigation, not its beginning. The beginning is the definition of "good."

What then, methodologically is this "good" that is to be "the notion upon which all Ethics depends?"23 It cannot be anything else but the axiom from which this science is to be deduced, so that the system itself is to be the structurization of that notion. At the same time, "good" must appear in the system as that variable which, applied to every case of goodness, determines the correctness of this application - just as, say, "force" in physics is that variable which, applied to every case of force, determines the correctness of this application-and at the same time forms the axiom of the Newtonian system.

This conclusion is inescapable if what Moore says about "good" and its role in the science of Ethics is to be taken seriously. No doubt, Moore takes seriously what he says; and, according to him, good has all the characteristics of the axiom of that science.

This question, how 'good' is to be defined, is the most fundamental question in all Ethics. That which is meant by 'good' is in fact, except its converse 'bad,' the only single object of thought which is peculiar to Ethics. Its definition is, therefore, the most essential point in the definition of Ethics....Unless this first question be fully understood, and its true answer clearly recognized, the rest of Ethics is as good as useless from the point of view of systematic knowledge....It is extremely unlikely that the most general ethical judgments will be valid in the absence of a true answer to this question. And, in any case, it is impossible that, till the answer to this question be known, anyone should know what is the evidence for any ethical judgment whatsoever. But the main object of Ethics, as a systematic science, is to give correct reasons for thinking that this or that is good; and unless this question be answered, such reasons cannot be given. Even, therefore, apart from the fact that a false answer leads to false conclusions, the present inquiry is a most necessary and important part of the science of Ethics. ${ }^{24}$

Moore maintains that Ethics is to be a systematic science, it is to be applied to all cases of goodness, and it is to be based on the notion "good." It is difficult not to conclude from these statements that the notion of "good" is to form the axiom of the science of Ethics. If this is conceded, then important consequences follow. (1) As force is in physics a formula applicable to physical reality, so "good" in Ethics must be a formula applicable to moral reality. (2) Since no such formula can be applied by itself but each scientific application of a formula involves the application of the whole system of which it forms a part, ${ }^{25}$ in each 
application of "good" the whole system of Ethics must be applied. (3) This means that this system must be so structured as to cover the whole field of value phenomena, just as physics is so structured as to cover the whole field of physical phenomena. Ethics, in other words, must be isomorphous with value reality. (4) The variable "good" within this system determines what things, and that things, are good. "Good," in other words, is that variable whose values are goods.

We must examine how Moore's science of Ethics can fulfill all these requirements. To do so we must start with the axiomatic role Moore outlines for "good."

To summarize, an axiom is defined as a formula that gives rise to a frame of reference applicable to reality. By a frame of reference I mean any formal system. A frame of reference applicable to reality is then the theoretical part of an exact science, a science such as physics and chemistry, "in their absolute distinction from those of which history and geography are instances." The practical part of such a science is the reality interpreted by the frame of reference in question. To use notions of conceptual logic, the theoretical part of the science may be regarded as the intension, and the practical part as the extension, of the axiom; in this way, an exact science may be sufficiently defined as the intension and extension of an axiom. ${ }^{26}$

The intension and extension of an axiom vary in direct proportion, whereas those of a concept vary in inverse proportion. As the extension, or applicability, of a science grows, so grows its theoretical framework in intension, that is, complexity. ${ }^{27}$ The axiom comes about by the identification of the core of a phenomenal field with the element of a formal system. For example, the science of optics is based on the identification of a ray of light with a straight line. The ray of light is the core phenomenon of the optical field, and the straight line is an element of the system of geometry. By this identification geometry becomes applicable to rays of light, and optics becomes possible. Every exact science is based on such an axiomatic identification. In order for phenomena to be equated with a formal element (or a set of such elements), they must appear in such a form as to be accessible to symbolic manipulation; they must appear as configurations of symbolic characters. These symbolic characters represent their primary properties. The axiom of an exact science is an equation containing sets of primary properties combined with sets of formal elements.

To create an exact science three principal steps are necessary: to break down the phenomena and their secondary properties into primary properties, to find the axiomatic identification in question, and to build up again the subject in the new form prescribed by the axiom. This is the classic method of resolution and composition, of analysis and synthesis, described by scientists such as Galileo Galilei, ${ }^{28}$ Sir Isaac Newton, ${ }^{29}$ and Albert Einstein ${ }^{30}$ by philosophers such as René Descartes, ${ }^{31}$ Gottfried Wilhelm Leibniz, ${ }^{32}$ Immanuel Kant, ${ }^{33}$ and Nicolai Hartmann ${ }^{34}$ by mathematicians such as Jacques Hadamard ${ }^{35}$ and Raymond Poin- 
care $;{ }^{36}$ and by the psychologists of creative thinking. ${ }^{37}$ Many of these authors made significant contributions to understanding the process of axiomatization in its logicai, epistemological, or psychological aspects. Descartes contributed the doctrine of the simples, Leibniz that of identities. Kant contributed the difference between the analytic and synthetic methods (philosophy and science, respectiveiy), with their respective concepts, the abstracted and the constructed; their respective definitions, the analytic and the synthetic (the axiomatic); and their respective judgments, analytic, synthetic, and synthetic a priori. Nicolai Hartmann contributed the doctrine of conspective and stigmatic intuition, and the psychologists that of the five stages of the process: Preparation, Frustration, Incubation, Illumination, and Verification.

Moore himself made use of the analytic-synthetic method. His two great discoveries, the naturalistic fallacy and the syntheticity of all propositions with "good," are both based on this method. To understand fully Moore's contribution to and position in the making of a systematic Ethics, all aspects of the method ought to be investigated. Then we can determine with precision how clear was his vision of that science, how far he came in the process of analysis of moral phenomena, how far in the identification of the axiom of the science, and how far in its synthesis.

Such an investigation is beyond the scope of this chapter, but the principal results will now be presented. Moore completed the first stages of the processanalysis-and reached about half-way into the second stage, that of axiomatic identification, without fully completing the identification. He said that "good" depends on the descriptive properties of the thing in question, even that it follows from them, but not that it is this set of descriptive properties. He clearly but not distinctly recognized the axiomatic character of what he said about "good" for the science of Ethics that he projected. He did not begin the actual construction of that science and was aggressively incomprehensive of others' attempts to find a logical structure in his writings on value. ${ }^{38} \mathrm{We}$ shall next examine in detail how far Moore's notion of "good" has the characteristics of an axiom for the science of Ethics.

Every creator of a science must be convinced of the following requirements: (1) the science is possible and its primitive notion knowable; (2) propositions with this notion are self-evident; (3) all propositions of the science must rest for their evidence on such self-evident propositions; (4) all propositions of the science are synthetic (indeed, synthetic a priori); (5) the primitive notion is subject to formal structurization; and (6) the formula of such structurization must be provided.

Moore's account of the notion of good fulfills all these requirements, even the sixth, in the following ways:

A. Moore's "good" is unknown but not unknowable.

B. Propositions with "good" are self-evident. 
C. All ethical propositions must rest for their evidence "upon some proposition which must be simply accepted or rejected."

D. All propositions with "good" are synthetic.

E. "Good" is subject to formal structurization.

F. The formula for this structurization is provided by Moore.

Let us discuss each of these points in turn.

\section{A. "Good" is Unknown but Not Unknowable.}

The indefinability of "good" is based, in Moore, on two observations: (a) good is so simple a notion that it cannot be defined and (b) it is so clear a notion that it need not be defined. Neither of these means that good cannot be known beyond the immediate intuition of it. On the contrary, if this intuition is clear, then it must also be capable of becoming distinct. And if it is to be the basis of a systematic science then it must be made distinct. As Leibniz indicated,

Knowledge is either obscure or clear; clear knowledge is either confused or distinct....A concept is obscure which does not suffice for recognizing the thing represented, as when I merely remember some flower or animal which I have once seen but not well enough to recognize it when it is placed before me and to distinguish it from similar ones; or when I consider some term which the Scholastics had defined poorly, such as Aristotle's entelechy,...or other such terms of which we have no sure definition. A proposition also becomes obscure when it contains such a concept.

Knowledge is clear, therefore, when it makes it possible for me to recognize the thing represented. Clear knowledge, in turn, is either confused or distinct. It is confused when I cannot enumerate one by one the marks which are sufficient to distinguish the thing from others, even though the thing may in truth have such marks and constituents into which its concept can be resolved. Thus we know colors, odors, flavors, and other particular objects of the senses clearly enough and discern them from each other but only by the simple evidence of the senses and not by marks that can be expressed. Yet it is certain that the concepts of these qualities are composite and can be resolved, for they certainly have their causes. ${ }^{39}$

Kant and Leibniz both recognized that distinct knowledge may either be analytic or synthetic. It is analytic when I succeed in enumerating "one by one the marks which are sufficient to distinguish the thing from other"; it is synthetic when

there are no marks but I obtain these only by synthesis. Out of this synthetic procedure arises the synthetic distinctness which augments my 
concept through additional marks found beyond it in (pure or empirical) intuition. This synthetic procedure of making a distinct concept is used in mathematics and in natural science,

whereas the analytic procedure, of "making a concept distinct," is used in philosophy. ${ }^{40}$

Let us apply these canons to the kind of knowledge Moore has of good. Obviously, it is clear, but confused. Moore knows clearly that there is good, but he does not discern distinctly what it is. He does not distinguish its features. How could it become distinct? Not analytically, for, as Moore insists, good is a simple notion and has no parts. Thus, it can be made distinct only synthetically. This means that its differentiation would result in a science such as mathematics and natural science-precisely the kind of science that for Moore is the prototype of the sciences of Ethics and Casuistry. Instead of making the notion of "good" distinct, the task is to make a distinct such notion, not to recognize what is given in the notion, but to construct such a notion, and this is a matter not of analysis but of synthesis. The result would be a new deductive science, not simply discerning common properties in empirical data.

Moore envisages precisely such a science-not an empirical science like geography, but a systematic one like physics. This science must give exact and explicit knowledge of the moral realm. "It is the business of Ethics, I must insist, not only to obtain true results, but also to find valid reasons for them. The direct object of Ethics is knowledge and not practice." ${ }^{\prime 1}$ But if Ethics is to be a systematic science, and if it is to give this kind of knowledge, and if this science is to be based on the notion of good, then this notion must be capable of elaboration; for a systematic science is systematic precisely by virtue of its fundamental notion being systematically developed. If all that can be said of good is that it is good "and that is the end of the matter," then this would necessarily be the end of the "science" of Goodness.

Moore's argument against naturalism is that it obstructs scientific ethical knowledge; naturalism is not distinct but confused, and it is not even clear-not even indistinctly - but obscure: "It offers no reason at all, far less any valid reason, for any ethical principles whatever; and in this it already fails to satisfy the requirements of Ethics, as a scientific study." 42 In offering "no reason at all" for "any ethical principle whatever" naturalism-as indeed any pre-scientific, that is pre-Moorean, ethics-does not see the subject matter of Ethics at all clearly but merely obscurely, as a term "poorly defined," not only in Aristotle and the Scholastics, but "in almost every book on Ethics." ${ }^{43}$ In seeing Ethics obscurely and not clearly, naturalists can "far less" give any valid reasons for it. What obstructs the philosophers' - as against the ethical scientists'-vision of goodness pure and simple is a fundamental logical confusion: they confuse goodness with what is good; thus they confuse predicate with subject, genus with 
species, one logical type with another. It is like defining an orange as yellow and holding "that nothing can be yellow but an orange."

We should not get very far with our science, if we are bound to hold that everything which was yellow, meant exactly the same thing as yellow. We should find we had to hold that an orange was exactly the same thing as a stool, a piece of paper, a lemon, anything you like. We could prove any number of absurdities; but should we be nearer the truth? Why, then, should it be different with 'good'? ${ }^{44}$

The naturalistic fallacy was discovered by Moore precisely in his effort to bring orderly thinking into the subject matter of Ethics. It is a legitimate fallacy, and it is the characteristic of post-Moorean ethics to have either ignored or misunderstood it, and, in any case, to have continued to commit it as if Moore had never existed. Among the misinterpretations is to say, with William K. Frankena, that it is the "definist fallacy" and hence absurd. It is not a fallacy to define good; it is, in case one defines it, to define it falsely, namely by confusing logical orders. To deny that good is indefinable involves a fallacy only because it involves contradictions. ${ }^{45}$ Frankena, in refuting the naturalistic fallacy, commits an ignoratio elenchi. ${ }^{46}$

This fallacy, according to Moore, not only obstructs the vision of "almost all" ethicists to the true nature of Ethics, it also deludes them "into accepting ethical principles which are false." ${ }^{, 47}$ It makes their knowledge of Ethics not only obscure but also erroneous, which means that they regard as clear what is obscure, thus closing their minds against all further inquiry. Since their obscurity is based on a logical fallacy, their error is a logical one; they regard as true what is false. ${ }^{48}$ Thus false ethics arise. When we are not so deluded we are at least not trapped into falsehood. "Good" is better not defined than defined falsely. If

we once recognize that we must start out Ethics without a definition, we shall be more apt to look about us, before we adopt any ethical principle whatever; and the more we look about us, the less likely are we to adopt a false one. It may be replied to this: Yes, but we shall look about us just as much, before we settle on our definition, and are therefore just as likely to be right. But I will try to show that this is not the case. If we start with the conviction that a definition of good can be found, we start with the conviction that good can mean nothing else than some one property of things; and our only business will then be to discover what that property is. But if we recognize that, so far as the meaning of good goes anything whatever may be good, we start with a much more open mind. ${ }^{49}$

The indefinable nature of "good" serves Moore as a guard against error and a guarantee for a more distinct knowledge in Ethics. 
The question then is, why did Moore think that his intuition that good is good was the end of the matter? The answer is that his argument for the indefinability of good rests on a mistaken view of definition. "The most important sense of 'definition," 'he tells us, "is that in which a definition states what are the parts which invariably compose a certain whole; and in this sense 'good' has no definition because it is simple and has no parts." ${ }^{.50}$ As an example of such a definition Moore cites that of "horse."

We may, when we define Horse, mean that a certain object, which we all of us know, is composed in a certain manner: that it has four legs, a head, a heart, a liver, etc., etc., all of them arranged in definite relations to one another. It is in this sense that I deny good to be definable. I say that it is not composed of any parts. ${ }^{51}$

This is an analytic definition that enumerates the secondary properties of the thing defined. Such a definition can never be one on which a systematic science can be based. Such a science, for example, physics or chemistry, in its absolute distinction from sciences such as history or geography, is based on a synthetic definition. Only such a definition can be the basis of a synthetic system: axiomatic identification of formal with phenomenal elements in their schematic form of primary properties. Moore's confusion in this respect appears in his inclusion of physiology among such sciences as physics and chemistry. He probably added this science as an afterthought, to prepare the way for his example of the horse. Physiology, while it does deal with general structures-with horse rather than this or that horse-does not deal with structures of primary qualities according to a frame of reference that makes the possession of these qualities by the things in question necessary and hence predictable. That horses have "four legs, a head, a heart, a liver, etc., etc.," are not synthetic a priori propositions, as are the propositions of physics, chemistry, and other exact sciences. Physiology is a purely empirical science. It is not even Casuistry in Moore's sense, for there is no theoretical part to it, as mathematics is to applied physics and chemistry, and as Ethics, the science of good, is to Casuistry. Thus, that good is not a notion like horse is irrelevant, for "good" as the "fundamental term" of the science of Ethics cannot possibly be an analytic term. It must be a synthetic term. Good, in other words, is not unanalyzable because it has no parts but because it is not analytic.

The notion of analytic definition is not the most important sense of "definition" to be applied to "good" if "good," as Moore insists, is the fundamental notion of the systematic science of Ethics. Rather, the most important sense of definition applicable to that notion is that of synthetic definition - that definition, namely, which originates a system of thought capable of serving as the theoretical part of an applied systematic science.

In the analytic-synthetic method, the given is resolved into absolutely simple notions out of which the subjects of inquiry are recomposed in the 
schematic form of their primary properties, and "in an order different from that in which we should regard them when considered in their more real nature." 52

An analytic definition is the beginning of this process, the very first step of breaking down the subject matter. In this very first step the analytic definition is the most important sense of "definition." In the science of good, the analytic method would consist in assembling data, such as uses and mentions of the word "good," sifting through them by the hundreds and thousands, and distilling from them the one element, unique and simple, that all these uses have in common, the absolute simple in the Cartesian sense, that bridges analysis and synthesis.

This analysis has three sources: everyday uses, philosophic mentions, and lexicological and etymological expositions (for example, the 135 uses mentioned in the Oxford English Dictionary, and the 528 quarto columns in Grimms Worterbuch der Deutschen Sprache). Moore employs only one of these sources, the second.$^{53}$ This "simple" is pregnant with meaning, and out of its components, if and when found, the new science would be built up. The distillation of this element must be preceded and accompanied by the conviction that there is such a common element, that good is good, and that it can be found. This is the intuition Moore expressed in Principia Ethica. It is the intuition that accompanies the analytic process of breaking down the moral data, and this analysis is what Moore performs in moral philosophy.

\section{B. Propositions with "Good" are Self-evident.}

Moore's use of the word "intuition" is largely the same as the rationalists' use: "Intuition" is a logical notion; it is not a psychological or even an epistemological one. An intuition is not a state of soul one suffers or an insight one proffers, but a proposition one offers. "I am not an 'Intuitionist," Moore said, "in the ordinary sense of the term," ${ }^{\prime 4}$ namely, in the sense of the nineteenth-century. But he may be called an intuitionist in terms of the seventeenth-century. He is concerned with the intuition that is the base of a new science. He discusses his intuitionism in connection with his endeavor "to write a "Prolegomena to any future Ethics that can possibly pretend to be scientific." "In other words," he continues, "I have endeavored to discover what are the fundamental principles of ethical reasoning; and the establishment of these principles, rather than of any conclusions which may be attained by their use, may be regarded as my main object." "s5 This means that he is not engaged in the synthesis that constitutes the new science nor, strictly speaking, in the analysis that leads up (or down) to it, but in the fundamental insight that creates it.

This intuition stands between the analysis and the synthesis of the subject. This notion divides Ethics as a philosophy from Ethics as a science. As end point of analysis it is a "simple" in the Cartesian sense; as starting point of the science it is a principle, a not-yet-articulated axiom. What Moore calls "conclusions" from the principle are merely corollaries of it. They do not follow from the 
meaning of the principle but merely from its existence-from the fact that it is, not what it is. They are not connected with the content of the principle but with its being the principle, to wit, "that very many different things are good and evil in themselves, and that neither class of things possesses any other property which is both common to all its members and peculiar to them."

Although this property, "good" (or "evil") is simple and unanalyzable, Moore from the very beginning tried to give it, and thereby the principle of scientific Ethics, some context. In Principia Ethica, he identified " $x$ is good" with " $x$ ought to exist for its own sake." What this means, though, can only be known by an intuition. "I have tried to show exactly what it is that we ask about a thing when we ask whether it ought to exist for its own sake, is good in itself or has intrinsic value." ${ }^{\text {" }} 7$ For answers to this question

no relevant evidence whatever can be adduced: from no other truth, except themselves alone, can it be inferred that they are either true or false. We can guard against error only by taking care, that, when we try to answer a question of this kind, we have before our minds that question only and not some other or others. ${ }^{58}$

Moore clearly regards answers to this kind of question in the same way that Descartes regards simple natures. Like Descartes, Moore emphasizes the complete concentration necessary for intuitive insight (as in the beginning of the Third Meditation: "I shall now close my eyes. I shall stop my ears, I shall avert my senses...."). ${ }^{59}$ Each thing must, so to speak, be taken as its own axiom, and this kind of proposition is what Moore calls intuition. "When I call such propositions 'Intuition,' I mean merely to assert that they are incapable of proof; I imply nothing whatever as to the manner or origin of our cognition of them." ${ }^{\prime \prime 0}$

This means that Moore's "intuitions" are not psychological. They are not even epistemological. Their truth does not depend on the insight by which they become manifest. "Still less do I imply (as most intuitionists have done) that any proposition whatever is true, because we cognize it in a particular way or by the exercise of any particular faculty." ${ }^{61}$ Self-evidence, as Moore is "anxious" to clarify,

means properly that the proposition so called is evident or true, by itself alone; that it is not an inference from some proposition other than itself. By saying that a proposition is self-evident, we mean emphatically that its appearing so to us, is not the reason why it is true: for we mean that it has absolutely no reason. ${ }^{62}$

The reason that a self-evident proposition lacks is a logical reason-its being incapable of proof. Hence, an intuition is a logical matter. We may have psychological or epistemological reasons for holding it, or even axiological reasons for 
why we ought to hold it that make it worthy of being thought, that is, "axioma." But all these reasons are not the logical reasons whose lack makes the proposition self-evident. ${ }^{63}$

Not only the truth but also the untruth of propositions may be self-evident. "In every way in which it is possible to cognize a true proposition, it is also possible to cognize a false one." ${ }^{64}$ Thus, the untruth of the proposition "Pleasure alone is good" is self-evident. "There is no logical reason for [declaring it untrue]... because there is no proper evidence or reason of its falsehood except itself alone. It is untrue because it is untrue."

Yet, there is something more to self-evidence than merely self-evidence. There is a pattern of self-evident propositions. With reference to the same proposition, the tenet of Intuitionistic Hedonism, Moore says: "I could do nothing to prove that it was untrue; I could only point out as clearly as possible what it means and how it contradicts other propositions which appear to be equally true." 66

Thus, self-evident propositions may be self-evidently true or false, and hence self-evidently contradict each other. This means that at least one element of self-evidence is the relation of the proposition to other such propositions in the same context, that is, the position of the proposition in the pattern of selfevident propositions in question. The self-evidence of ethical propositions is at least in part due to the consistency of the pattern of these propositions, and this pattern is, precisely, the systematic science of Ethics. The self-evidence of the fundamental notion of good propagates itself, so to speak, to all the propositions forming the system.

A mere "notion," no matter how clearly held, cannot originate a system. It must be distinctly held in order to do so. It must be articulated into some one proposition that forms the axiom of the system.

\section{All Ethical Propositions Must Rest for Their Evidence "Upon Some Proposition Which Must be Simply Accepted or Rejected"}

All judgments, says Moore, that this or that is good (or bad) "must rest in the end upon some proposition which must be simply accepted or rejected, which cannot be logically deduced from any other proposition." ${ }^{77}$ This means that all such judgments-Moore also calls them "ethical propositions"-are derived from some one proposition and thus are interrelated with respect to that one proposition. All such judgments form a system, and the proposition upon which the system rests in the end is the axiom of the system: that Proposition, namely, by virtue of which the system (a) is a system, (b) is the system of Ethics, and (c) all the propositions within it are ethical. Again Moore makes all this clear but without making it distinct. The axiomatic characteristics of the Proposition with its consequent system in Moore's work are these: (a) it is a proposition; (b) it cannot be logically deduced from any other proposition; hence, (c) it is self- 
evident; (d) it must be simply accepted or rejected; (e) it is the fundamental principle of the system of Ethics; ( $f$ ) all ethical propositions "must rest" on it "in the end" (which means that they must be derived from it); ( $\mathrm{g}$ ) all ethical propositions are contained in the system; and $(h)$ they all receive their character of being ethical from the Proposition.

Let us now examine all these characteristics in Moore's text. For brevity's sake we will use his summary statement: "My discussion hitherto has fallen under two main heads. Under the first I tried to show what 'good' - the adjective 'good'-means." ${ }^{68}$ The upshot of this discussion was that "good is good and nothing else whatever, and that naturalism was a fallacy." ${ }^{69}$ But Moore has not shown what good means, only that it means. And it may mean "anything whatever." ${ }^{70}$ To give it some one particular meaning involves the fallacy in question. Logically, this could be interpreted as meaning that good is a variable which confers its meaning - whatever it be-on anything to which it is significantly applied. The only meaning Moore gives to this variable is that its range is that of Ethics. Hence, any proposition " $x$ is good" is an ethical proposition. This kind of "meaning" is not that of an adjective or a predicate; it is that of a notion that establishes a systematic science. It is the meaning of "the notion upon which all Ethics depends."

The variable "good," thus, determines (a) the field of Ethics as such and (b) the content of this field as ethical. Moore makes clear this double significance of "good." To know what good means, he says, "appeared to be the first point to be settled in any treatment of Ethics that should aim at being systematic. It is necessary we should know this, should know what good means...for two reasons." "The first is that "good" establishes the science of Ethics, the second that it determines its content as ethical.

The first reason is that 'good' is the notion upon which all ethics depends. We cannot hope to understand what we mean, when we say that this is good or that is good, until we understand quite clearly, not only what 'this' or 'that' is (which the natural sciences and philosophy can tell us) but also what is meant by calling them good, a matter which is reserved for Ethics only. Unless we are quite clear on this point, our ethical reasoning will be always apt to be fallacious. We shall think that we are proving that a thing is 'good' when we are really only proving that it is something else; since unless we know what 'good' means, unless we know what is meant by that notion in itself, as distinct from what is meant by any other notion, we shall not be able to tell when we are dealing with it and when we are dealing with something else, which is perhaps like it, but yet not the same. ${ }^{72}$

Thus, the notion of good determines the field of Ethics. This is what Moore calls "the first steps in our ethical method." 73 
A second step was taken when we began to consider proposed selfevident principles of Ethics. In this second division, resting on our result that good means good, we began the discussion of propositions asserting that such and such a thing or quality or concept was good. Of such a kind was the principle of Intuitionistic or Ethical Hedonism - the principle that 'Pleasure alone is good.' Following the method established by our first discussion, I claimed that the untruth of this proposition was self-evident. ${ }^{74}$

Its untruth is self-evident because it contradicts the evident truth of the fundamental notion, that good is good and not another thing. Thus, the second reason why we must know what "good" means is that every ethical proposition depends on it. This second reason is one of method: every proposition within the science depends on that notion.

And the second reason why we should settle first of all this question 'What good means' is one of method. It is this, that we can never know on what evidence an ethical proposition rests, until we know the nature of the notion which makes the proposition ethical. We cannot tell what is possible, by way of proof, in favor of one judgment that 'This or that is good', or against another judgment that 'This or that is bad', until we have recognized what the nature of such proposition must always be. ${ }^{75}$

Thus, "good" is the point of origin of the science of Ethics and the point of reference of every ethical proposition. It is "the ground of all definition in Ethics" as well as of the definition of "Ethics."

There is a simple indefinable unanalyzable object of thought by reference to which [Ethics] must be defined. By what name we call this unique object is a matter of indifference so long as we clearly recognize what it is and that it does differ from other objects. The words which are commonly taken as the signs of ethical judgments all do refer to it; and they are expressions of ethical judgments solely because they do so refer. ${ }^{77}$

Part of Ethics - as Casuistry - is "to enumerate all true universal judgments asserting that such and such a thing was good, whenever it occurred,"78 that is, to determine the range of the variable "good."

If "All ethical propositions must rest in the end upon some proposition which must be simply accepted or rejected," then "such propositions are all of them, in Kant's phrase, 'synthetic.",79

\section{All Ethical Propositions are Synthetic}

The syntheticity of "good" is regarded by Moore, besides the naturalistic fallacy, as the most fundamental of his discoveries. "Propositions about the good are all 
of them synthetic and never analytic; and that is plainly no trivial matter." ${ }^{180} \mathrm{~A}$ proposition "about the good" is a proposition of whose subject it is said that "it is good." "The good" is the class of subjects, and "good" is the predicate of the propositions. Such propositions "must be synthetic propositions, declaring what things, and in what degree, possess a simple and unanalyzable property which may be called intrinsic value or goodness. ${ }^{.81}$ At the same time, such propositions rest upon some one proposition that answers the question not "What things are good?" but "What is goodness?" This fundamental proposition, we have seen, must be the axiom of the science of Ethics. But it cannot be itself "synthetic"; rather it is the Proposition by reference to which ethical propositions become synthetic. What then is the Proposition itself "in Kant's phrase?"

As the axiom of the science of Ethics, it is what Kant calls a synthetic definition. It defines "good." 82 Hence, "good" cannot be the predicate; it must be the subject or the definiendum, depending on how one interprets "is" in the expression "'Good' is..." Actually, Moore's "meaning of 'good"' is precisely this expression: "Good' is"- and nothing else. "Good" is whatever it is. It is a variable and this expression, "Good' is," is not synthetic or, for that matter, a proposition.

Are the derived universal propositions (those of the form " $(x) x$ is good," for example, "All pleasures are good") synthetic propositions? If they all rest on the Proposition that determines "good" and if this Proposition establishes the systematic science of Ethics, then all these propositions must be not only, in Kant's phrase, synthetic, but also synthetic a priori. They must be synthetic in the sense that "good" cannot be part of the content of any subject whatsoever - except one that is itself part of the system of Ethics (as against Casuistry).

The situation is the same with any predicate that makes a proposition synthetic a priori. "Triangular," for example, cannot be the subject of any proposition except one within the system of Geometry, one namely which determines triangularity; nor can it be part of the content of any subject except one that belongs to the system, for example, "cone." Whenever "triangular" appears in any other proposition, namely of applied geometry, that proposition is synthetic a priori. "Triangular," precisely because it belongs to the system of Geometry, cannot be part of the content of any subject that does not belong to that system. This can also be expressed by saying that "triangular" is a primary and not a secondary property. For the same reason "good" cannot be part of the content of any subject whatsoever except one that belongs to the system of Ethics, for example, "value," and it cannot be the subject of any proposition except one within the system, namely one which determines goodness. "Good," in other words, is a primary property belonging to Ethics, and not a secondary property belonging to Casuistry.

Whenever it is said that "This or that is triangular," the whole system of Geometry is involved; in general, in the application of any system, the whole system is involved. ${ }^{83}$ The involvement of a whole system is what makes this kind 
of proposition synthetic a priori. Their predicates are borrowed from the system and carry, so to speak, the whole system with them into the proposition, like a snail carries its house. In exactly the same sense, "good," in Moore's sense, carries the whole system of Ethics with it into any proposition of the form "This or that is good." Such propositions are applied ethical propositions, belonging to Casuistry, and for this very reason are all synthetic a priori. ${ }^{84}$

The fact that "good" when used as a predicate makes the proposition synthetic (and indeed synthetic a priori) leads to a further important consequence for the meaning of "good." It involves the distinction in kind between good and any property that can be the content of an analytic concept. But this immediately raises the question, what is the relation between good and such analytic properties? This question concerns the structure of a complex that includes good.

\section{E. "Good" May be Subject to Formal Structurization}

That there is a structure to goodness Moore already suggested by classifying "good" with number. Number obviously has a structure, and the analogy with number and reference to this structure pervades the whole latter part of Principia Ethica. "It is quite certain that two natural objects may exist; but it is equally certain that two itself does not exist and never can." ${ }^{85}$ Here Moore alludes to what may be called the naturalistic fallacy in the field of mathematics - a fallacy which had to be eradicated in that field in a similar way which it had to be in Ethics in order to make it scientific. ${ }^{86}$ The meaning of good and the meaning of number show a parallel structure. Number is number and not another thing; in particular, it is not anything that is numbered. To confuse the two, as had been done constantly, is a logical fallacy.

Another equally fundamental similarity exists between good and number. "Two and two are four. But that does not mean that either two or four exists. Yet, it certainly means something. Two is somehow although it does not exist."87 But what is this "isness" of two? It is its being part of the system of Mathematics. Similarly, the "isness" of "good" is its being part of the system of Ethics. In both cases, this systematic or ideal "isness" has, "by metaphysicians," been confused with a kind of existence, not natural but supernatural. In this confusion Moore finds again fertile soil for the "naturalistic fallacy" - which in this aspect ought to be called the "super-naturalistic fallacy." Metaphysicians cannot content themselves with the idea that numbers are just numbers or good just good. "It is beyond their power to believe that what you do mean is merely what you say."88 They hypostatize both, making them states of God's or somebody else's mind and thus are like the empiricists who cannot be content with this simple idea either, but make number and good dependent on the existence of things. ${ }^{89}$

Both kinds, the naturalistic and the supernaturalistic, are fallacies of confusing logical levels: either the predication of something with what it is predicated of, or the holding of something with what is held (as in the various 
"states" mentioned by Moore). The naturalistic and the super-naturalistic fallacy are one and the same kind of logical fallacy, and this fallacy is applicable to both number and goodness. These are neither natural nor supernatural but non-natural entities. Actually, the fallacy is found in any field in the process of transition from philosophy to science. It is a fallacy the commission and the excision of which is inherent in the scientific method. Whenever a notion is to be structured as a system applicable to reality, the philosophical stage consists in confusing the notion with the reality. In Kantian terms, the fallacy consists in confusing synthetic, that is constructed "data," with analytic, that is given data, whether given a posteriori or a priori. The constructed and the given follow different orders, not only in the sense of Kant, but also in that of Descartes, and even that of Russell. Moore's fallacy, in the last analysis, is a fallacy of confusing logical orders.

Moore is correct when he says that errors in Ethics are like errors in Mathematics. "The only difference is that in Ethics, owing to the intricacy of its subject matter, it is far more difficult to persuade anyone either that he has made a mistake or that that mistake affects his result." ${ }^{\text {90 }}$

Moore, then, is a rationalist in Ethics. No wonder that he did not remain content with the mere clarity of his intuition of "good" but proceeded, step by step, to distinctness. Already in Principia Ethica he gives a structurization of good that contains, in germ, the exact determination of it he gave twenty years later. This characterization, derived from the synthetic nature of good and the fact that it is not a secondary property, is that an experience of good contains within it sets of secondary properties.

We find this structure in Moore's discussion of the Ideal, as summum bonum, and related to the discussion of the super-naturalistic fallacy. In this fallacy the manifestation of something and that of which it is a manifestation are confused. These are two different things and may have two different values. Indeed, says Moore, the value of the manifestation bids us do what we ought to do, rather than the ought itself. "If...the moral maxim is to be justified it is the existence of this manifestation as distinguished from the existence of its corresponding [eternal] reality, which must be truly good." ${ }^{91}$ Similarly, in his discussion of the summum bonum, Moore maintains the value of material existence. Idealistic philosophers

have usually represented a purely spiritual state of existence as the Ideal. Regarding matter as essentially imperfect, if not positively evil, they have concluded that the total absence of all material properties is necessary to a state of perfection.... But it does not follow, from this superiority, that a perfect state of things must be one, from which all material properties are rigidly excluded: on the contrary, if our conclusions are correct, it would seem to be the case that a state of things, in which they are included, must be vastly better than any conceivable state in which they were absent. In 
order to see that this is so, the chief thing necessary to be considered is exactly what it is which we declare to be good when we declare that appreciation of beauty in Art and Nature is so. That this appreciation is good, the philosophers in question do not for the most part deny. But, if we admit it, then we should remember Butler's maxim that: Everything is what it is, and not another thing. I have tried to show, and I think it is too evident to be disputed, that such appreciation is an organic unity, a complex whole; and that, in its most undoubted instances, part of what is included in this whole is a cognition of material qualities, and particularly of a vast variety of what are called secondary qualities. If, then, it is this whole, which we know to be good, and not another thing, then we know that material qualities, even though they be perfectly worthless in themselves, are yet essential constituents of what is far from worthless. ${ }^{92}$

Although "Good" is, as an intuition, a simple unanalyzable object, Moore says enough of it to make it not only clear but increasingly distinct: "Good" is the basis of the science of Ethics. As such it forms the unknown axiom of that science. It makes all ethical propositions synthetic, which means, since it is the element of a systematic science, synthetic a priori. It is not itself a secondary quality, but any complex experience with it is an organic unity that includes a vast variety of secondary qualities. These insights are sufficient for Moore to combine them, twenty years later, into a formula that determines goodness with precision.

\section{F. The Formula for the Structurization of "Good" is Provided by Moore}

In "The Conception of Intrinsic Value" Moore formulates the two structural elements he recognized in good in his "Prolegomena" - that all propositions with "good" are synthetic and that any experience of goodness contains sets of secondary properties-in the following striking (and to him paradoxical) manner: "Two different propositions are both true of goodness (1) that it does depend only on the intrinsic nature of what possesses it...and (2) that, though this is so, it is yet not itself an intrinsic property. ${ }^{93}$ This formula, derived from an elucidation of the relation between a thing's intrinsic nature and its value quality, contains the two elements of the structure of goodness discerned in Principia Ethica, further differentiated. At the same time, this differentiation gives rise to puzzles, unsolved by Moore, that point to an ultimate sense of the formula that eluded him.

Moore's position gives rise to three particularly striking puzzles: (1) Both natural intrinsic and value properties are said to "depend" on the intrinsic nature of what possesses them. What is the difference between the two senses of "depend"? (2) Both propositions are said to be true of goodness, that it is not an intrinsic property and that it depends solely on the intrinsic properties of what 
possesses them. How is this possible? (3) Natural intrinsic properties are said to describe the thing in question to some extent while value properties are said not to describe the thing to any extent at all. What is the particular sense of "describe" here used?

The first part of the formula, that good depends only on the intrinsic nature of what possesses it, determines the relation between "good" and the set of the secondary qualities in a more distinct manner than was attempted in Principia Ethica. By "intrinsic nature" is meant, precisely, the set of these qualities. Whereas in Principia Ethica Moore says that within a complex whole that is good the secondary qualities play an essential role,"though they be perfectly worthless in themselves, [they] are yet essential constituents of what is far from worthless," he now says, that for goodness itself they play an essential role, and he determines this role more precisely: goodness depends, and it depends only, on this set. What was left to find out in order to make the relation fully clear was how goodness thus depends. Moore never gave the solution to this question, but he came close enough to it for us to be able to supply this missing link.

The second part of the formula says that though goodness depends only on the set of secondary properties of what possesses it, it is yet not itself such a property. This part of the formula corresponds to the synthetic nature of "good." Any secondary predicate may be part of a thing that is good; thus a proposition with it may be analytic; but any proposition with good must never be analytic. Hence "good" cannot itself be a secondary property or an intrinsic property in the terminology of "The Conception of Intrinsic Value." This makes the nature of the dependence of good on the analytic properties with respect to which it is synthetic even more enigmatic.

How can a property not belong to a set of properties, hence make synthetic any proposition whose subject represents that set, and yet depend only on that set-which means for the proposition in this respect not to be synthetic? Obviously, the relation must be between analytic and synthetic-and this means it must be synthetic a priori. ${ }^{94} \mathrm{~A}$ term that makes a proposition synthetic a priori does not depend on the subject's content but it does depend only on the system of which it is a part, which provides the necessary connection between subject and predicate. Now, if good, according to Moore's formula, is not a part of the set of the natural intrinsic properties of the thing and yet depends only on that set, then it must follow from my analysis that this set itself must be the system of which good is a part! And this system of natural intrinsic or secondary properties must itself be, or be part of, the system of Ethics.

This is the solution of Moore's paradox of goodness.

\section{The Axiomatic of the Science of Value}

Moore, in "The Conception of Intrinsic Value," gives another differentiation of the relationship between the natural and the value properties of a thing. This 
relation, he shows, is an a priori one. Twenty years later, forty years after Principia Ethica, he says that it is a logical relation. ${ }^{95}$ While the dependence of the pleasantness of a thing on the intrinsic natural properties is an empirical one, that of the goodness of the thing on these properties is a necessary one, indeed, it is the logical relation "follows from."

'Pleasant' is being so used that the proposition that experiences with those intrinsic properties are pleasant to me, or other or all men, is merely an empirical proposition, not a necessary one. Whereas the question: What makes this experience good? is equivalent to the question: From what intrinsic characteristics of this experience does it follow that it is good?, and the proposition that experiences with those intrinsic properties are good is not an empirical but a necessary one. ${ }^{90}$

I will now answer this question - what makes this experience good? - and in such a way that the puzzles Moore left unsolved will fall into place. In particular, I will show how my answer explains: (1) in which way both the natural and the non-natural intrinsic properties "depend" on the intrinsic nature of what possesses them, (2) in which way the "two different propositions" that are "both true of goodness" are both true of it, and (3) what particular sense of "description" is used by Moore. At the same time, my answer will show in what way the system of secondary properties is the system of which "good" is a part.

Moore's question is: "From what intrinsic characteristics of this experience does it follow that it is good?" My answer is: From all of them. A thing's goodness follows logically from the possession of all its intrinsic properties.

By intrinsic properties of a thing I understand these properties that correspond to the predicates contained in the thing's concept. Thus, I may re-phrase my answer and say that a thing is good if its properties correspond to the predicates of its concept. Or, a thing is good if it fulfills its concept. No matter how this answer be phrased, it is immediately clear what is meant. And it is evident that a thing that has all the properties named in its concept is a good such thing. A good horse is a thing called "horse" having all the horse properties; a thing called a lyre having all the properties of a lyre is a good lyre. It is also clear that this answer is nothing but the logical formulation of a principle common to all traditional value theory, whether expressed in ontological, teleological, epistemological, or any other terms.

Ontologically, a thing has been called good in the degree of its perfection; teleologically, in the degree of fulfilling its purpose; epistemologically, in the degree of possessing its essential properties. It is called good to the degree that its actuality corresponds to its ideality, or its ideality is fulfilled in its actuality (Paul Weiss) and to the degree that there is "fulfillment of its essential nature" (Paul Tillich). Moore himself at one time formulated this principle when he said that a thing is good when it has "the special complex of characters which justify 
us in calling it good."97 Surveying the history of axiology, we have here a general consensus, an axiologia perennis. It becomes theologia perennis when the notion of specific perfection is generalized into the perfection of an absolute being that lacks nothing and has the abundance of all properties. ${ }^{98}$ Thus, Moore's tortured penetration into the mystery of goodness comes out, in the end, as the classic principle of it, formulated, for example, by Cicero, who wrote,

It is not merely Justice and Injustice which are distinguished by nature, but also and without exception things which are honorable and dishonorable. For since an intelligence common to us all makes things known to us and formulates them in our minds, honorable actions are ascribed by us to virtue and dishonorable ones to vice; and to think this to be a matter of opinion rather than a rule of Nature is insane. For even what we, by a misuse of the term, call the virtue of a tree or a horse, is not based on opinion, but on Nature. ${ }^{99}$

In Moore, this principle appears in such a logical form as to make it capable of serving as the axiom of a science of value. In the course of history, especially in scholastic rationalistic philosophy, the term "Nature" took on precisely the logical meaning that corresponds to Moore's "intrinsic nature," namely "set of properties of a thing." 100

This logical form solves the problems Moore left to us.

First, it shows the difference between the two senses of "depend," both of the natural intrinsic properties, and of the value property, on the intrinsic nature of the thing in question. The sense of "depend" of the natural intrinsic properties is conceptual containment: they are contained in the set of predicates that constitute the intension of the thing's concept. By this set the thing is thought of as one, and its properties are thought of as those of its intrinsic nature. The "depend" of the value predicate, by contrast, is the relation of entailment. The value predicate "good" is entailed by the total set of the intrinsic natural properties, that set which corresponds to the intensional set of predicates of the thing's concept. Goodness itself entails that the thing which possesses it has the total set of its natural intrinsic properties. Thus, the relation between the two kinds of properties is equivalence. ${ }^{101}$

Second, Moore's formula of the two different propositions, both true of goodness, that determine the relationship between the natural and the non-natural properties, has two aspects, a positive and a negative, both of which are determined with reference to description. The positive aspect is that any non-natural property depends solely on the intrinsic nature of the thing in question, that is, on the set of the descriptive properties of the thing. The negative aspect is that this non-natural property must contribute nothing at all toward the description of the intrinsic nature of the thing. "So strong are these requirements that one may reasonably doubt whether any properties which actually meet them are ever 
to be found." ${ }^{102}$ My axiom meets these requirements. It solves the paradox of the formula in the way any paradox is solved, namely, by distinguishing the two logical orders represented by the two aspects in question.

Moore's formula says that goodness does, at the same time, depend only on the descriptive properties of the object and yet not describe the object at all. This is obvious according to the vicious circle principle. If "good," in the sense of this principle, "involves" 103 the totality of descriptive properties, as it does, then "good" cannot possibly itself be a member of the set, that is, it cannot possibly describe. This means that "good" is on a higher logical level than any of these properties. This means that "good" cannot be, primarily, a predicate of the subject of a descriptive predicate; it must, at least, be a predicate of the concept of such subject. This means that when we understand that a thing "is good," it is not necessary that we know anything of the thing in question, but we must know something of the concept of which the thing is an instance.

Whenever the word "good" is used, a logical operation is performed. The properties contained in the concept of the thing in question are combined with the idea of the particular thing called good. Its having these properties makes it good. A thing is good if it fulfills the intension of its concept. Any value proposition with "good" as predicate means that the subject has all its conceptual predicates. The proposition is synthetic, for the property of having all the intrinsic properties is not, and never can be, itself one of these properties; and it is synthetic a priori if the definition of good serves as the axiom of the science of value, which Moore called the "science of Ethics."

The definition is appropriate for serving as this axiom for it is the articulation of Moore's clear but indistinct notion of good. It articulates this notion in terms of an axiomatic identification: it identifies the core of the phenomenal realm of value with the elements of a formal system, namely the notions of intension and class membership in logic. Thus, the system of logic becomes available for the structuring of the field of value. The definition is synthetic in Kant's sense: it gives rise to a system of axiology; all axiological propositions rest on it in the sense of being derived from it. ${ }^{104}$

Third, the puzzle of the sense of description in question is resolved in an unexpected way. Full sets of descriptive predicates correspond to the value good, while less than full such sets to the values less than good (fairness, average, badness, and so on). This means that subsets of the set of descriptive properties -including this set itself-are values of the thing. A value property then is $a$ subset of the set of descriptive properties. Valuation, in other words, is the combinatorial play with properties. In valuation we leave out of account the normal set of secondary properties of the thing, that by which the thing is defined or generally known as a fact, and freely combine and recombine the elements of this set. Such combinations and recombinations of secondary properties are values. As elements of values the secondary properties of fact become the primary property $p$, and all the subsets of this set are values; so there are $2^{p}-1$ 
values of the thing. This means that fact is the set, namely $p$, in terms of which the totality of subsets, that is values, is being ordered. Fact thus appears as the ordering norm of value. Moreover, since the set $p$ may be seen as its own subset-it is part of the totality $2^{p}-1$-the value goodness is the set of intrinsic natural properties seen as a subset of itself. In this sense it is true that goodness is a part of the system of secondary properties.

Moore's lifelong puzzlement about the relation between goodness and the set of natural intrinsic properties was well justified. His question about the sense in which natural intrinsic properties describe and non-natural such properties do not has this answer: Natural properties describe as primary value properties. ${ }^{105}$

The systematic science to be developed from these beginnings can be shown to have applications for ethical propositions as well as other value propositions. It is Casuistry in Moore's sense. It defines both intrinsic value and extrinsic value, as well as the fields in which they are used. Thus, Moore's intuition that there is a unique object, good, that is the fundamental term of a systematic science of Ethics does appear to be justified. Good is, as he suggested, the fundamental notion of a formal science. The axiomatic identification mentioned structures both this notion and the science. In it, "good" appears as a logical or a syncategorematic term. Thus, as expressed recently, "Moore's intuition was an intuition of the syncategorematicity of the meaning of 'good."'106

Principia Ethica, then, appears as a treatise on the unknown axiomatic character of "good." It is, to some degree unconsciously, an exercise in the analytic-synthetic method of creating a new science. It may well be said, therefore, that its "end of the matter" is at the same time the beginning of the matter. It is an analytic end but a synthetic beginning, a categorial end but an axiomatic beginning, a philosophical end but a scientific beginning.

Good is indefinable analytically, but not synthetically; it cannot be defined as a concept but it can be defined as a construct. It is not a philosophical category but it may well be a scientific axiom. It is the end of Ethics as philosophy, which Moore convincingly showed to be based on a logical fallacy, and the beginning of Ethics as a science, to which he wrote the "Prolegomena." Ethics, and value theory in general may indeed, in their structure, become exact sciences like physics and chemistry. And Principia Ethica, while not Principia in the sense of Newton, may yet be principia, in the sense of being a new beginning in moral philosophy, as was Newton's Principia in natural philosophy. They may yet play their part in making true Newton's prediction, in his discussion of the analytic-synthetic method: "And if natural Philosophy in all its Parts, by pursuing this Method, shall at length be perfected, the Bounds of Moral Philosophy will also be enlarged." 107

Envisaging a moral science is no idle dream. In doing so, we must be clear about the levels of language in which value phenomena can be discussed. These levels, as already said, provide the axiological fallacies. We now see that they 
also provide the solution of Moore's paradox of Goodness. The following pages will show that they are the ordering matrix for moral philosophies.

The next two parts will present a classification and critique of value theories, first extensively, then intensively. In Part Two, the relation between value and reason(s) will be examined in a reasonably complete survey of contemporary value theories. In Part Three, the same relation will be studied in depth: formal value theory will be applied to the goodness of reasons given for valuation, in a sample of value theories. 